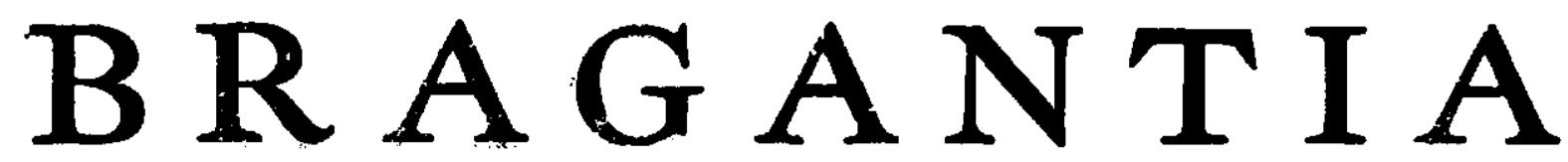

Boletim Técniço da Divisão de Experimentação e Pesquisas INSTITUTO AGRONÔMICO

Vol. 5

Campinas, Fevereiro de 1945

N.० 2

\title{
TRATAMENTOS DE SEMENTES DE MILHO
}

\section{G. P. Viégas}

\section{INTRODUČ̃̃O}

Que vantagens há, para o plantador de milho, em fazer o prévio tratamento das sementes empregadas? Qual é, das drogas existentes, no comércio, a mais conveniente?

É óbvio que as vantagens esperadas se devem refletir, em última análise, num compensador aumento nas colheitas, resultante provàvelmente de um melhor "stand", ou, então, na obtenção de um produto mais sadio. A sanidade pode-se avaliar por uma menor proporção de espigas podres (atacadas por moléstias) ou menor percentagem de plantas acamadas, pois é sabido que um dos fatôres determinantes do acamamento são as podridões dos colmos das plantas.

Resultados experimentais - Assim pôsto, o problema foi sendo estudado experimentalmente no período de 1940 a 1944 . Nos primeiros quatro anos agrícolas foram conduzidas experiências em Campinas.

No ano agrícola de 1939/40 comparou se o comportamento de duas variedades: Armour e Itaici, ambas do tipo dente-amarelo, tratadas e não tratadas com o mesmo ingrediente: Abavit sêco a 0,2\%.

O plano adotado foi o seguinte:

PLANO: 3 blocos ao acaso.

Canteiros : 4 linhas de $10 \mathrm{~m}$ de comprimento espaçadas a $1,20 \mathrm{~m}$; as covas a $0,30 \mathrm{~m}$. Plantar três sementes por cova e deixar uma planta no desbaste. 
Tratamento:

1. Var. Armour sem Abavit a 0,2\%

2. Var. Armour com Abavit a 0,2\%

3. Var. Itaici sem Abavit a 0,2\%

4. Var. Itaici com Abavit a 0,2\%

O ensaio foi plantado em 27-11-39, sendo boa e uniforme a germinação. Houve, entretanto, um ataque de lagartas, que prejudicou o "stand" da experiência. A análise estatística dos dados revelou que as diferenças entre os tratamentos não foram significativas. Em média, os canteiros plantados com sementes da variedade Armour, tratadas, produziram $153 \mathrm{~kg} / \mathrm{ha}$ a mais do que os não tratados; por outro lado, para a variedade Itaici, nos sem Abavit a produção foi $348 \mathrm{~kg} / \mathrm{ha}$ maior.

No ano de 1940/4l resolvemos estudar a germinação, não só no campo como no laboratório e, ao mesmo tempo, com quatro diferentes drogas, a saber: Uspulum sêco a 0,2\%, Granosan a 0,1\%, Semesan Jr. a $0,2 \%$, Abavit sêco a 0,2\%, em comparação com sementes não tratadas, da variedacie Armour.

$O$ plano adotado foi o seguinte:

PLANO : 4 blocos ao acaso.

Canteiros : $48 \mathrm{~m} 2$, isto é, com 4 linhas de $10 \mathrm{~m}$ de comprimento. Espaçamento de 1,20 × 0,30 m. Plantar 3 sementes por cova e deixar uma planta no desbaste. Colheita das duas linhas centrais de cada canteiro.

Variedade: Armour.

Tratamentos :

1. Uspulum sêco a $0,2 \%$

2. Granosan a 0,1\%

3. Semesan Jr. a $0,2 \%$

4. Abavit sêco a $0,2 \%$

5. Sem tratamento.

Pelos dados do quadro I pode-se notar que todos os canteiros cujas sementes foram tratadas (exceto com Granosan) produziram menos que os canteiros cujas sementes não foram tratadas.

As diferenças observadas foram pequenas e não significativas.

Pode-se notar ainda que nenhum dos ingredientes melhorou a germinação do milho, quer no germinador de rôlo ("rag-doll"), quer no campo. 
Bem assim, não se notaram diferenças favoráveis dos tratamentos, quanto ao número de plantas acamadas e percentagem de espigas atacadas por moléstias.

Em 1941/42 (*) foi repetida a experiência, tendo-se o cuidado de adotar novo sorteio para os canteiros. A análise estatística dos dados, confirmando os resultados anteriormente obtidos, revelou que as dis ferenças não foram significativas. Em $1942 / 43$ foi novamente repetida a experiência, com resultados também não significativos.

Os resultados dos três últimos ensaios foram analisados em conjunto e os dados obtidos figuram no quadro I (vide gráfico n. ${ }^{\circ} 1$ ).

\section{QUADRO I}

ENSAIOS DE TRATAMENTOS DE SEMENTES

CAMPINAS, 1941143

\begin{tabular}{|c|c|c|c|c|}
\hline \multirow{2}{*}{ TRATAMENTOS } & \multicolumn{3}{|c|}{ PRODUGÃO - GRAOS, Ka ha. } & \multirow{2}{*}{ MÉDIA } \\
\hline & $1940: 41$ & $1941 / 42$ & $1942: 43$ & \\
\hline $\begin{array}{l}\text { 1. Uspulum sêco a } 0,2 \% \ldots \\
\text { 2. Granosan } 0,1 \% \ldots \\
\text { 3. Semesan Jr. } 0,2 \% \ldots \ldots \ldots \\
\text { 4. Abavit sêco } 0,2 \% \ldots \ldots \\
\text { 5. Sem tratamento............ }\end{array}$ & $\begin{array}{l}3674 \\
3845 \\
3594 \\
3574 \\
3778\end{array}$ & $\begin{array}{l}2833 \\
1916 \\
2354 \\
2050 \\
2133\end{array}$ & $\begin{array}{l}3550 \\
3250 \\
3380 \\
3240 \\
2890\end{array}$ & $\begin{array}{l}3352 \\
3003 \\
3109 \\
2955 \\
2933\end{array}$ \\
\hline$d==$ & \pm 734 & \pm 563 & \pm 546 & \pm 441 \\
\hline
\end{tabular}

As diferenças observadas não foram significativas e, porisso, os aumentos de $419 \mathrm{~kg} / \mathrm{ha}(14 \%)$ a favor do Uspulum e de $176 \mathrm{~kg} / \mathrm{ha}$ (6\%) a favor do Semesan Jr. devem ser interpretados como ocasionais.

Para o ano agrícola de $1943 / 44$ foram projetados oito ensaios.

Nestas experiências, escolhemos, propositadamente, uma variedade bastante resistente à podridão das espigas -... Catêto - e outra variedade muito suscetível - Itaici.

Os ensaios foram planejados da seguinte forma: PI_ANO: 4 blocos ao acaso.

Canteiros: $48 \mathrm{~m} 2$, isto é, com 4 fileiras de $10 \mathrm{~m}$ de comprimento espaçadas a $1,20 \mathrm{~m}$; as covas $0,20 \mathrm{~m}$ e em cada cova semear três sementes, deixando, no desbaste, uma planta.

(*) De $1939 / 40$ a $1941 / 42$, as experiências foram executadas pelo colega Agron. N. A. Neme, a quem consignamos os nossos melhores agradecimentos. 
Adubar com fósforo e potássio à base de $80 \mathrm{~kg}$ de $\mathrm{P}_{2} \mathrm{O}_{5}$ e $50 \mathrm{~kg}$ de $\mathrm{K}_{2} \mathrm{O}$ por hectare, com farinha de ossos (com $28 \% \quad \mathrm{P}_{2} \mathrm{O}_{5}$ ) e carbonato de potássio (com $20 \% \mathrm{~K}_{2} \mathrm{O}$ ).

Tratamentos :
11. Uspulum sêco a $0,2 \%$ - var. Catêto
12. Granosan a
$0,1 \%$ - var. Catêto
13. Semesan Jr. a
$0,2 \%$ - var. Catêto
14. Abavit sêco a
15. Sem trat. ${ }^{\circ}$
$0.2 \%$ - var. Catêto
21. Uspulum sêco a
- var. Catêto
22. Granosan a
23. Semesan Jr. a
24. Abavit sêco a
25. Sem trat.
$0,2 \%$-... var. itaici
$0,1 \%$ - var. Itaici
$0,2 \%$ - var. Itaici
$0,2 \%$ - var. Itaici
-- var. Itaici

Foram analisados os ensaios instalados em Campinas, Mococa, Pindorama, Ribeirão Preto e Santa Rita. Todos êstes ensaios deram resultados não significativos. Particularizando:

Campinas - $O$ ensaio decorreu normalmente, sendo ótimo o "stand" final. Não se observaram diferenças favoráveis aos tratamentos, quer na germinação quer no número de plantas caídas, ou percentagem de espigas atacadas por moléstias, e produção. Note-se que a variedade Catêto produziu bem menos que a Itaici.

Mococa - O "stand" final foi um pouco baixo e as produções colhidas também pequenas. Devemos atender ao fato de que tais resultados são consequiência do plantio tardic, o que explica também porque, neste caso, Itaicí produziu menos que Catêto.

Pindorama - Os "stands" inicial e final foram ótimos. A variedade Itaici mostrou-se acentuadamente mais suscetível às podridões das espigas que a variedade Catêto. As produções observadas foram elevadas e maiores para a variedade Itaici.

Ribeirão Preto -. O "stand" foi bom. A variedade Itaici teve quase três vêzes mais espigas atacadas por moléstias que a Catêto. Apesar de relativamente grande a diferença a favor de Uspulum, ainda assim não foi signiticativa.

Santa Rita - Os "stands" na germinação e colheita, segundo informações em nosso arquivo, foram bons. As produções observadas foram muito altas.

Os dados da produção figuram no quadro II (vide gráfico 2) e, em média, podemos afirmar que, para a variedade Catêto, os melhores 


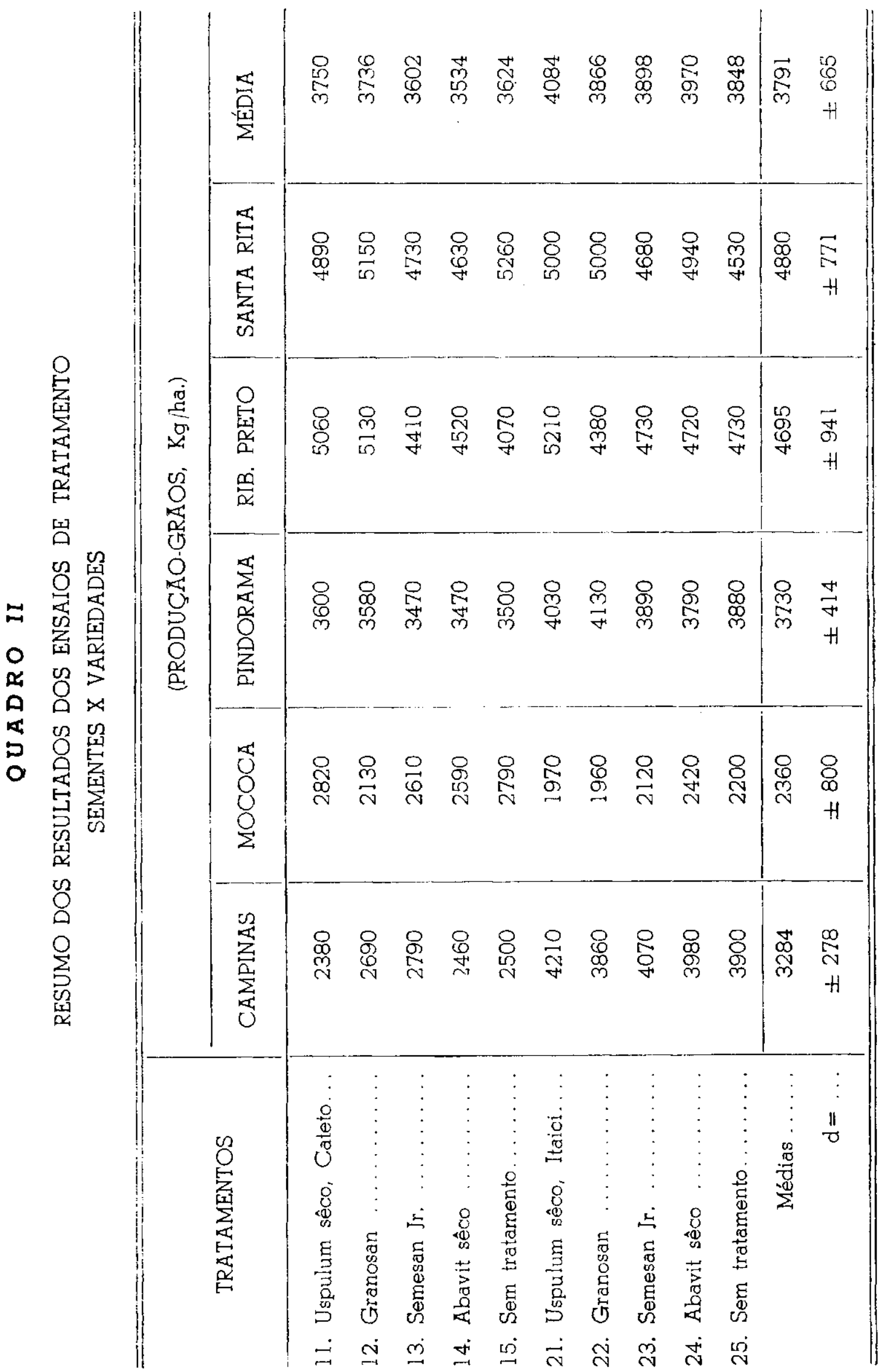




\section{RESULTADO MÉDNO DOSENSAIOS DE TRATAMENTOS DE SEMENTES DEMILHO EM TRES ANOS CONSECUTIVOS}

CAMPINAS 1940/47 a $1942 / 43$ PAODUCOEES DE GRAOS EM QUILOS P/HECTARE

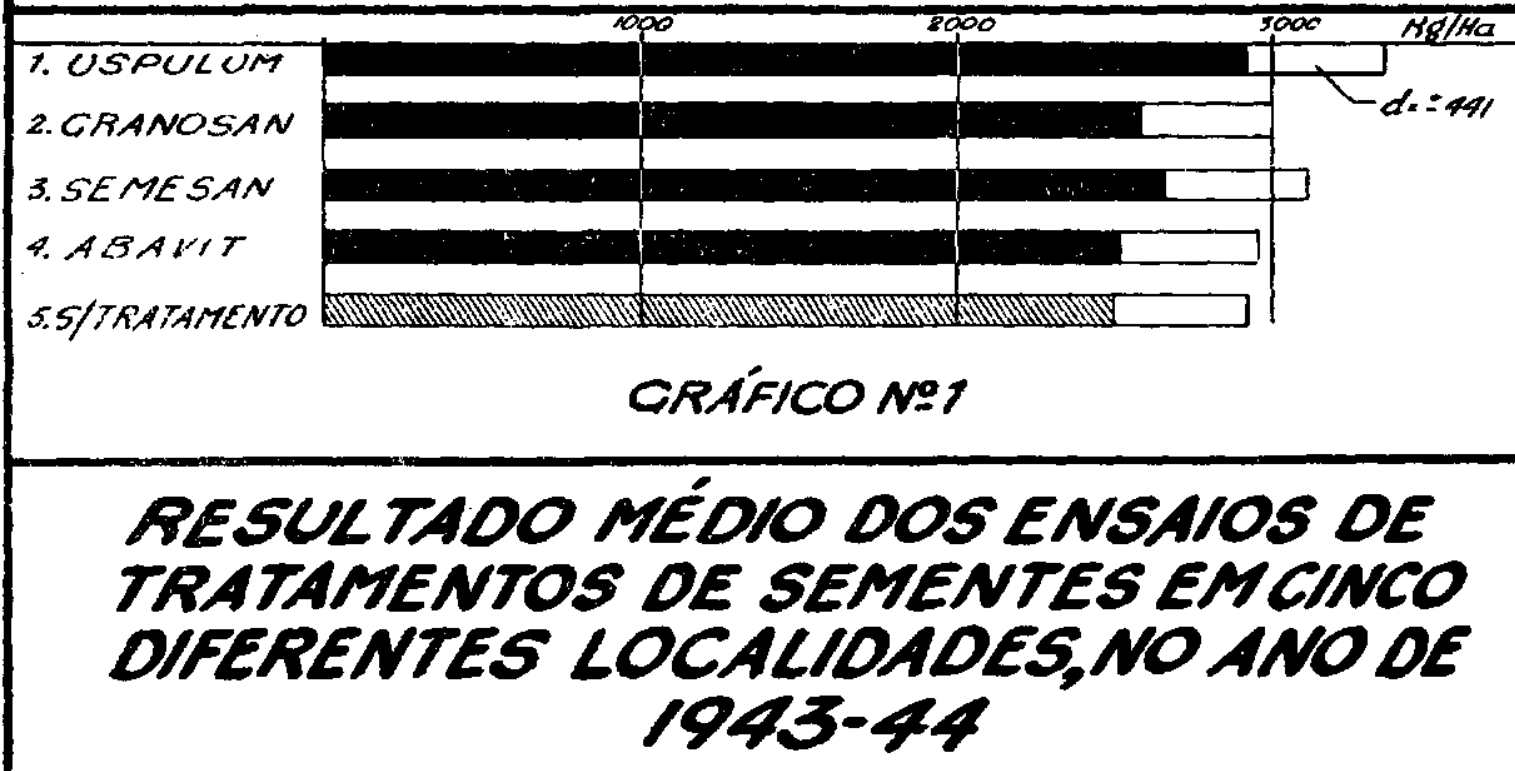

PRODUCOOES DE CRAOS EM QULLOS PIHECTARE

11. USPULUM T2.GRANOSAN 13.5EME SAN J! 19. $A B A Y I T$ 15.5ITAATAMENTO 21. USPULUM 22. GRANOSAN 23.SEMESAN $J$ R 24. ABAVIT 25.5/TRUTAFENTO

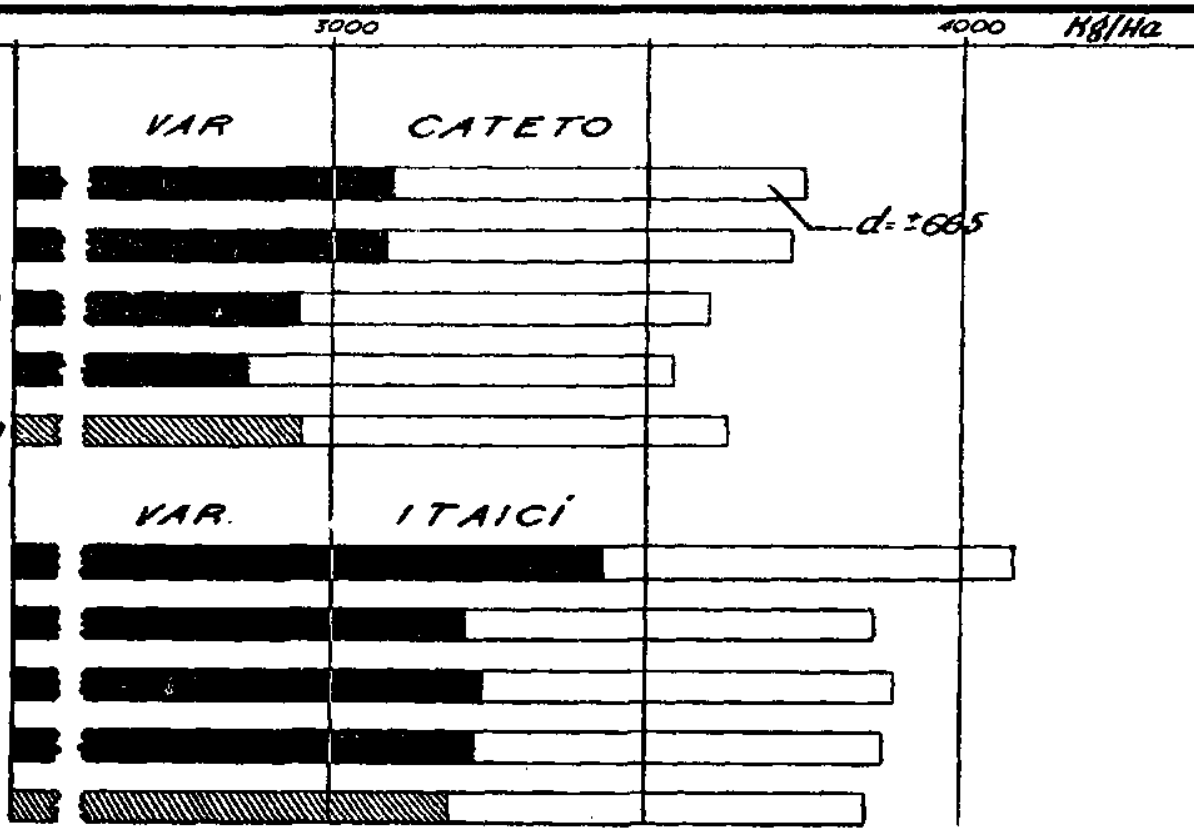


tratamentos foram Uspulum e Granosan, que determinaram um aumento de $126 \mathrm{~kg} / \mathrm{ha}(3 \%)$ na produção.

Para a variedade Itaici, o Uspulum determinou um aumento de $236 \mathrm{~kg} / \mathrm{ha}(6 \%)$. Estas diferenças, numa análise conjunta dos cinco ensaios, não são ainda signiticativas.

Podemos, pois, afirmar que, à vista dos dados experimentais, os tratamentos de sementes de milho, com vários ingredientes, não determinaram melhor produção ou melhor sanidade ao produto colhido.

\section{RESUMO E CONCLUSÕES}

Investigou-se, em experiências de campo, a ação de vários ingredientes utilizáveis no tratamento de sementes de cereais. $\bigcirc$ trabalho, abrangendo um perícdo de 5 anos, foi realizado com 3 variedades comuns de milho, e em diversas localidades do Estado, compreendendo 9 ensaios, ao todo.

$O$ único ingrediente que deu indicações mais consistentes de melhorar a produção, foi o Uspulum a 0,2\%.

Mas, em definitivo, não se pode afirmar que os ingredientes empregados melhoraram a produção ou a sanidade do produto colhido, julgando-se pela percentagem de espigas atacadas por moléstia. Não se notou melhoria na germinação ou menor número de plantas acamadas. 